\title{
Persistent and new-onset anaemia in children aged 6 - 8 years from KwaZulu-Natal Province, South Africa
}

T P Gwetu, ${ }^{1} \mathrm{MB}$ ChB, MPH; M Chhagan, ${ }^{1}$ FCPaed (SA), PhD; M Craib, ${ }^{1} \mathrm{MB}$ ChB; $\mathbf{M}$ Taylor, ${ }^{1} \mathrm{PhD}$;

S Kauchali, ${ }^{1,2}$ FCPaed (SA), MS, MPhil (Epidemiology)

Department of Public Health Medicine, School of Nursing and Public Health, College of Health Sciences, University of KwaZulu-Natal, Durban, South Africa

${ }^{2}$ Department of Paediatrics and Child Health, School of Nursing and Public Health, College of Health Sciences, University of KwaZulu-Natal, Durban, South Africa

Corresponding author: T P Gwetu (tgwetu@gmail.com)

\begin{abstract}
Background. Anaemia impairs normal development in children and has wide-ranging social and economic implications. Existing anaemia control strategies primarily target anaemia in infancy. The contribution, however, of anaemia in preschool- and school-aged children as well as its long-term effects has not been extensively evaluated.

Objectives. To determine the prevalence of anaemia in the same children on two occasions at least 18 months apart.

Method. We carried out a longitudinal study in a rural community of KwaZulu-Natal, South Africa. Haemoglobin (Hb) levels were measured using the HaemoCue at baseline when the children were aged 4 - 6 years, and the follow-up assessment was done at age 6 8 years. HIV screening and helminth testing was offered to all the children.

Results. $\mathrm{Hb}$ levels at both baseline and follow-up were available for 181 children. The baseline anaemia prevalence was $56.9 \%$ (mean $\mathrm{Hb} 11.2$, standard deviation (SD) 1.14) and at follow-up the anaemia prevalence was $41.9 \%$ (mean Hb 11.7, SD 1.19). There were 21/180 (11.7\%) children with new-onset anaemia at follow-up, while anaemia from baseline persisted in 43/103 (41.8\%).

Conclusions. The findings suggest a high burden of anaemia in these school-aged children, which might be reduced with early interventions. Interventions targeting screening and management of anaemia, chronic infections and nutritional deficiencies are recommended.
\end{abstract}

S Afr J Child Health 2015;9(4):127-129. DOI:10.7196/SAJCH.2015.v9i4.929

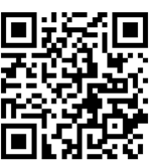

Anaemia impairs normal development in children and is implicated as both a cause and an effect of adverse social and economic family circumstances. ${ }^{[1]}$ Global estimates of childhood anaemia indicate that 293.1 million children aged $<5$ years are anaemic worldwide, with $28.5 \%$ of these living in sub-Saharan Africa. ${ }^{[2]}$ This high anaemia burden among children of sub-Saharan Africa is generally attributed to poverty, communicable diseases, food insecurity, HIV and other associated concerns such as access to healthcare and sanitation. ${ }^{[3]}$ In South Africa (SA), where poor nutrition, poverty and poor parental education are prevalent, the implications are severe for children's future and for national development.

Existing global solution strategies to control anaemia in early childhood such as micronutrient supplementation and breastfeeding support have been successful, though associated with questionable sustainability in terms of protecting children from developing anaemia after infancy ${ }^{[3]}$ A significant proportion of anaemia in school-aged children is attributed to iron deficiency. ${ }^{[2]}$ Subclinical iron deficiency is even more common and has comparable developmental consequences. In the present study, anaemia was used as an indicator of deprived nutrition and poor health status. This study was conducted in a rural community from KwaZulu-Natal (KZN) province where the children are disadvantaged by poor socioeconomic circumstances. Although the association between anaemia and poverty has been described by various researchers, ${ }^{[1,3]}$ the natural history of anaemia associated with poor social environments in young children is not yet well described.

\section{Methods}

\section{Study population}

This was a longitudinal survey in KZN. This research was an ancillary study to a larger cohort study investigating the health and psychosocial needs of children. The parent study enrolled 1787 children aged 4 - 6 years identified in a door-to-door survey in the Valley of a Thousand Hills. The current study was conducted when these children were undergoing follow-up assessments at ages of between 6 and 8 years. A total of 184 consecutive children over a 4-month period were invited to join this study.

\section{Diagnostic testing}

Haemoglobin $(\mathrm{Hb})$ determination by HaemoCue (Angelholm, Sweden) was conducted by a clinician. Anaemia was defined using $\mathrm{Hb}$ levels. The World Health Organization (WHO)-recommended cut-offs were used to classify anaemia severity. Children aged up to 59 months had an $\mathrm{Hb}$ cut-off of $11.0 \mathrm{~g} / \mathrm{dL}$, and $11.5 \mathrm{~g} / \mathrm{dL}$ was applied for children 5 - 11 years old. Children aged up to 59 months had anaemia categorised as mild for Hb levels $10.0-10.9 \mathrm{~g} / \mathrm{dL}$, moderate $7.0-9.9 \mathrm{~g} / \mathrm{dL}$ and severe $<7.0 \mathrm{~g} / \mathrm{dL}$, while for children 5 - 11 years of age anaemia was classified as mild with $\mathrm{Hb}$ levels $11.0-11.4 \mathrm{~g} / \mathrm{dL}$, moderate $8.0-10.9 \mathrm{~g} / \mathrm{dL}$ and severe $<8.0 \mathrm{~g} / \mathrm{dL}^{[4]}$ Stool and urine samples were collected and sent for microscopy at a local academic hospital. All caregivers and children were offered voluntary HIV counselling and testing.

\section{Analysis of time and treatment effects on anaemia}

This exploratory analysis utilised $\mathrm{Hb}$ measurements from two time-points: the baseline at enrolment into the parent study; and at 
follow-up, which occurred at least 18 months later. The two $\mathrm{Hb}$ measurements were used to determine the $\mathrm{Hb}$ trend over time. We assessed within-group differences for participants who had anaemia at these two time-points. Individual analyses were carried out for all the study participants. Parasitic infections were referred to as severe if the child had the presence of symptoms such as diarrhoea, abdominal pain and blood in stool. Asymptomatic cases were documented as mild.

\section{Statistical analyses}

SPSS version 22 software (IBM, USA) was used for data entry and analysis. The distribution of anaemia, and effect of infection and treatment were assessed using descriptive statistics and graphical plots. Characteristics of the children in each defined group were compared using Student's $t$-test and $\chi^{2}$ tests as appropriate.

\section{Ethical review}

This research study was approved by the University of KZN Biomedical Research Ethics Committee. Informed consent was obtained from the children's caregivers before enrolment. All children with $\mathrm{Hb}<10 \mathrm{~g} / \mathrm{dL}$ were referred for clinical intervention.

\section{Results}

\section{Population characteristics}

$\mathrm{Hb}$ levels at both baseline and follow-up were available for 181 of 184 (98.4\%) participants. At baseline, the children were aged 47 77 months (standard deviation (SD) 0.58) and at follow-up 72 - 102 months (SD 0.55). The study group comprised more males (109/184 (59.2\%)) than females. All children were asymptomatic for anaemia.

\section{Anaemia profile}

At baseline, the prevalence of anaemia was 103/181 (56.9\%). Among the anaemic, 2/103 (1.9\%) children had severe anaemia, 62/103 (60.2\%) moderate and 39/103 (37.9\%) mild. A significant declining trend was seen at follow-up, with an anaemia prevalence of $76 / 181(42 \%)$, with $1 / 76(1.3 \%)$ severe anaemia, 45/76 (59.2\%) moderate and 30/76 (39.5\%) mild ( $p=0.002)$. Generally, there was a trend towards a higher mean $\mathrm{Hb}$ with time for all children (Table 1). The mean (SD) $\mathrm{Hb}$ at follow-up (11.7 (1.19) g/dL) was higher than at baseline (11.2 (1.14 g/dL) $(95 \%$ confidence interval (CI) $-0.71--0.23)$ ). Of the non-anaemic children at baseline, 21/78 (26.9\%) were anaemic at follow-up. Among the anaemic children at baseline, 43/103 $(41.8 \%)$ were still anaemic at follow-up. The two children who had severe anaemia at baseline did not have anaemia at follow-up. Of the 62 with moderate anaemia at baseline, $27 / 62(43.6 \%)$ persisted with anaemia. Of the children with anaemia at baseline, 14/103 (13.6\%) were found to have lower Hb levels at follow-up, with one child who initially had $\mathrm{Hb} 11.1 \mathrm{~g} / \mathrm{dL}$ present with severe anaemia $(\mathrm{Hb} 6.6 \mathrm{~g} / \mathrm{dL})$ at follow-up.

At baseline, 27/103 (26.2\%) children with $\mathrm{Hb}$ $<10 \mathrm{~g} / \mathrm{dL}$ were referred for clinical intervention at their local clinic. At follow-up, 18/27 (66.7\%) children were still anaemic, although 23/27 (85.2\%) had improved $\mathrm{Hb}$ levels. Of the children with persistent anaemia, 7/27 (25.9\%) continued to have $\mathrm{Hb}$ levels $<10 \mathrm{~g} / \mathrm{dL}$ despite referral for clinical management.

\section{Clinical factors \\ HIV infection}

A total of $168 / 181$ (92.8\%) children were tested for HIV at baseline and 3/168 (1.8\%) were HIV-positive. Two of these children had mild anaemia at baseline. A non-significant increased uptake for HIV testing was seen at follow-up (179/181 (98.9\%)), with 5/179 (2.8\%) children testing positive for HIV infection. HIV-positive children had a trend towards lower $\mathrm{Hb}(11.22 \mathrm{~g} / \mathrm{dL}, \mathrm{SD} 0.81)$ than HIV-negative children (12.19 g/dL, SD 1.19) children (95\% CI -4.27 - -1.32). At followup, all five HIV-infected children were anaemic with an $\mathrm{Hb}$ range of $8.0-11.4 \mathrm{~g} / \mathrm{dL}$ : 2 mild, 2 moderate and 1 severe anaemia.

\section{Parasitic infection}

A total of 52/181 (28.7\%) children had a history of expelled worms prior to the assessment. Of these, 49 (94.2\%) had mild asymptomatic infections and 2/52 (3.8\%) had severe symptomatic infections. The age of the children at the time of expelling the worms ranged from 7 to 60 months, with a mean (SD) age of 31 (13.1) months. A total of $107 / 181$ (59.1\%) participants had received deworming treatments within the past 12 months. Of these, 37/107 (34.6\%) were anaemic at follow-up. A total of 178/181 (98.3\%) urine and stool samples were tested for parasitic infection in the second survey. Microscopy was positive for parasites in 43/178 (24.2\%) children, although only $31 / 178$ (17.4\%) had pathological infection. Pathogens identified were Ascaris lumbricoides (10/31 (32.3\%)), Giardia lamblia (18/31 (54.8\%)), Blastocystis hominis (1/31 (3.2\%)), Enterobius vermicularis $(2 / 31(6.5 \%))$, Trichuris trichiura (1/31 (3.2\%)), Entamoeba coli (8/31 (25.8\%)) and Schistosoma haematobium (3/31 (9.4\%)). Of the children with parasitic infection, 14/31 (45.2\%) had anaemia compared with $31 / 147$ (21.1\%) without helminth infection. Anaemia trends for individual pathogens were Ascaris spp. (3/10 (30.0\%)), S. haematobium (1/3 (33.3\%)), G. lamblia (9/18 (50.0\%)), E. coli $4 / 8$ $(50.0 \%)$ and $B$. hominis $0 / 1$. The contribution of parasite infestation to anaemia was statistically significant $(p=0.03)$. Deworming had a significant effect on anaemia at followup $(p=0.01)$.

\section{Exploratory analysis of the trend in} anaemia and haemoglobin over time There was no statistical difference in anaemia between those who had been referred for treatment and those who had not (Table 2). The
Table 1. Change in haemoglobin levels according to anaemia presence at baseline

\begin{tabular}{llll}
\hline & $n$ & $\begin{array}{l}\text { Mean change in Hb g/dL between follow- } \\
\text { up and baseline, mean }(95 \% \mathrm{CI})\end{array}$ & $p$-value \\
\hline Anaemic at baseline & 103 & $0.47(0.18-0.75)$ & 0.002 \\
Non-anaemic at baseline & 78 & $0.40(0.12-0.69)$ & 0.006 \\
All participants & 181 & $0.47(0.23-0.72)$ & 0.000
\end{tabular}

Table 2. Children with anaemia at baseline and at follow-up stratified according to HIV status and treatment arm

\begin{tabular}{lllll}
\hline & & \multicolumn{2}{c}{ Participants with anaemia, $n(\%)$} & \\
\cline { 3 - 4 } & $n$ & Baseline & Follow-up & $p$-value \\
\hline HIV status & & & & \\
HIV-infected & 179 & $100(55.87)$ & $71(39.66)$ & 0.13 \\
HIV-uninfected & & & & 0.00 \\
Parasitic infection & 107 & $55(51.40)$ & $37(34.60)$ & 0.01 \\
$\quad \begin{array}{l}\text { Dewormed } \\
\text { Not dewormed }\end{array}$ & 74 & $48(64.86)$ & $39(52.70)$ & 0.07 \\
Anaemia status & & & & \\
Treatment received & 103 & $27(26.21)$ & $10(9.71)$ & 0.19 \\
$\quad$ No treatment received & 76 & $76(73.8 \%)$ & $45(43.69)$ & 0.13
\end{tabular}


researchers did not explore the differences between HIV-infected children because of the small sample size. Children who received deworming treatment had a trend towards higher mean increase in $\mathrm{Hb}$ compared with children who did not receive deworming treatment. The mean difference between baseline and follow-up $\mathrm{Hb}$ levels for children who had been referred for treatment was $2.4 \mathrm{~g} / \mathrm{dL}$ (95\% CI 1.86 - 2.88) while the mean difference in $\mathrm{Hb}$ levels for those who had not received treatment was $0.7 \mathrm{~g} / \mathrm{dL}(0.39-1.07)$. This difference was clinically significant $(p<0.005)$.

\section{Discussion}

The prevalence of anaemia in this study population was high: $57.2 \%$ at baseline and $42.2 \%$ at follow-up. The researchers suggest that the high anaemia burden among this study population could be attributed to high levels of poverty, food insecurity and infectious diseases in the community. Anaemia persisted in $41.8 \%$ of children who were found to be anaemic at baseline. Moreover, over a quarter of initially non-anaemic children (26.9\%) developed anaemia (based on WHO criteria) over the 2-year interval. Concern regarding this high anaemia burden in school-aged children remains owing to the commonly asymptomatic nature of anaemia and the inadequate treatment rates for those children who do seek healthcare. This study found evidence to suggest that deworming has a beneficial effect on anaemia prevention, while clinical interventions to treat anaemia in earlier childhood may not prevent anaemia in later childhood. It is thought that the anaemia was related to iron deficiency and exacerbated by infections. This high prevalence of anaemia in schoolaged children highlights the need to consider additional strategies for anaemia control for this population.

The WHO, which compiled a systematic review of country-level data from 1993 to 2005, estimated a global anaemia prevalence of $25.4 \%$ (305 million children) among school-age children. ${ }^{[5]}$ Very few data were available on school-aged children in most African countries, including SA. For this global database to achieve maximum potential, investigations need to be carried out and additional information gathered on $\mathrm{Hb}$ levels in schoolaged children. The prevalence findings from this study were in stark contrast to the recent 2013 SANHANES- $1^{[6]}$ report, which described a very low anaemia prevalence of $10.5 \%$ in children up to 14 years old. However, the findings from the present study are more comparable with earlier national surveys ${ }^{[7,8]}$ and local studies, ${ }^{[9,10]}$ which reported anaemia prevalence ranging from 16.5 to $33 \%$. The ages of children assessed, methods of determining $\mathrm{Hb}$ concentration and anaemia $\mathrm{Hb}$-level cut-offs varied from those used in this current study. Hence, the outcomes on anaemia prevalence need to be compared with caution.

Although studies implementing micronutrient supplementation in early childhood as a primary prevention strategy have been encouraging, the findings from this study suggest that this strategy may not prevent anaemia in later childhood. The variety of treatments received and duration of treatment make comparisons challenging. Several studies have reported difficulties in finding adequate evidence to detect significant effects and the few trials available provided limited evidence of benefit. ${ }^{[1,12]}$

Anaemia burden was high among children with HIV and parasitic infections. This identifies these groups for targeted interventions. Strategies to increase uptake of HIV testing by caregivers need to be endorsed. The uptake for HIV testing (98.9\%) was higher than that reported by another local study $(41.0 \%) \cdot{ }^{[13]}$ Public health campaigns are needed to encourage HIV testing for children. Parents who miss the opportunity during pregnancy may be offered routine systematic testing of their children at later ages. Parasitic infestation was found in $17.7 \%$ children and contributed significantly to anaemia presence $(p=0.03)$. The re-infection rate following treatment was $24.3 \%$. The pathogens identified were comparable with other local studies, which reported variable parasitic infection of $T$. trichiura (53.9 - 86.2\%), A. lumbricoides (19.4 - 85\%), hookworm (20 -
83.2\%) and S. haematobium (24.5\%). ${ }^{[14-16]}$ The KZN helminth control programme is school based. By this age, a large proportion of the children are already affected by anaemia, hence the guidelines may require refinement in order to optimise benefits.

\section{Recommendations}

Global complementary efforts are necessary to promote good nutritional status and reduce common infections in children. Chronic anaemia, including iron depletion and anaemia of inflammation, needs to be addressed. The appropriate execution of the Integrated Management of Childhood Illness programme is expected to result in better case identification and management for children with anaemia. The Expanded Programme on Immunization (EPI) has also achieved good national coverage and may be an effective vehicle for the provision of interventions for controlling anaemia and infections in children up to school age. Interventions providing dietary support need to be complemented with attempts to increase screening and treatment for anaemia, helminth infection and HIV in children at risk. Long-term interventions and policies that target individual, community and national levels are needed, recognising the effect of different cultural practices and financial restrictions.

\section{References}

1. Lozoff B, Jimenez E, Hagen J, Mollen E, Wolf AW. Poorer behavioural and developmental outcome more than 10 years after treatment for iron deficiency in infancy. Paediatrics 2000;105(4):E51.

2. World Health Organization (WHO). Worldwide prevalence of anaemia 1993 - 2005: WHO global database on anaemia. Geneva: WHO, 2008. http:// whqlibdoc.who.int/publications/2008/9789241596657_eng.pdf (accessed 21 January 2015).

3. Soares Magalhães RJ, Clements ACA. Spatial heterogeneity of haemoglobin concentration in preschool-age children in sub-Saharan Africa. Bull World Health Organ 2011;89(6):459-468. [http://dx.doi.org/10.2471/BLT.10.083568]

4. WHO. Haemoglobin Concentrations for the Diagnosis of Anaemia and Assessment of Severity. Vitamin and Mineral Nutrition Information System. Geneva: WHO, 2011. http://www.who.int/vmnis/indicators/Hemoglobin.pdf (accessed 21 January 2015).

5. De Benoist B, McLean E, Egli I, Cogswell M, eds. Worldwide prevalence of anaemia 1993 - 2005. In: WHO Global Database on Anaemia. Geneva; WHO, 2008.

6. Shisana O, Labadarios D, Rehle T, et al. South African National Health and Nutrition Examination Survey (SANHANES-1), 2013. Cape Town: HSRC Press, 2013.

7. Labadarios D, van Middelkoop A. Children Aged 6 - 71 Months in South Africa, 1994: Their Anthropometric, Vitamin A, Iron and Coverage Status. Technical report. Johannesburg, South African Vitamin A Consultative Group, 1995. http://www.sahealthinfo.org/nutrition/vitamina.htm (accessed 21 January 2015)

8. Labadarios D, Swart R, Maunder EMW, et al. National Food Consumption Survey - Fortification Baseline (NFCS-FB-I) South Africa, 2005. S Afr J Clin Nutr 2008;21(3):56

9. Oelofse A, Faber M, Benadé JG, Benadé AJ, Kenoyer DG. The nutritional status of a rural community in KwaZulu-Natal, South Africa: The Ndunakazi project. Cent Afr J Med 1999;45(1):14-19.

10. Faber M, Jogessar VB, Benade AJS. Nutritional status and dietary intakes of children aged $2-5$ years and their caregivers in a rural South African community. Int J Food Sci Nutr 2001;52(5):401-411.

11. Chhagan MK, van den Broeck J, Luabeya KA, Mpontshane N, Tomkins A, Bennish ML. Effect on longitudinal growth and anaemia of zinc or multiple micronutrients added to vitamin A: A randomized controlled trial in children aged 6 - 24 months. BMC Public Health 2010;10:145.

12. Geltman PL, Meyers AF, Mehta SD, et al. Daily multivitamins with iron to prevent anemia in high-risk infants: A randomized clinical trial. Pediatrics 2004;114(1):86. [http://dx.doi.org/10.1542/peds.114.1.86]

13. Chhagan MK, Kauchali S, Arpadi SM. Failure to test children of HIV-infected mothers in South Africa: Implications for HIV testing strategies for preschool children. Trop Med Int Health 2011;16(12):1490-1494. [http://dx.doi.org/10.11 $11 / j .1365-3156.2011 .02872]$

14. Jinabhai CC, Taylor M, Coutsoudis A, Coovadia HM, Tomkins AM, Sullivan KR. Epidemiology of helminth infections: Implications for parasite control programmes, a South African perspective. Public Health Nutr 2001;4(6):12111219.

15. Saathoff E, Olsen A, Kvalsvig JD, Appleton CC. Patterns of geohelminth infection, impact of albendazole treatment and re-infection after treatment in schoolchildren from rural KwaZulu-Natal/South-Africa. BMC Infect Dis 2004;4:27. [http://dx.doi.org/10.1186/1471-2334-4-27]

16. Appleton CC, Mosala TI, Levin J, Olsen A. Geohelminth infection and reinfection after chemotherapy among slum-dwelling children in Durban, South Africa. Ann Trop Med Parasitol 2009;103(3):249-261. [http://dx.doi. org/10.1179/136485909X398212] 